\section{What is already known on this topic}

Most people want to be involved in decisions about their medical treatment, but many prescribing decisions are not shared. Patients' preferences are often different to those of clinicians, and may lead to choices contrary to guidelines

Little is known about the factors which clinicians or lay people use to decide whether to start preventive treatment

Guidelines are based on arbitrary judgments of what benefit is worthwhile

\section{What this study adds}

Understanding the numerical basis for decisions about preventive treatment is difficult for both clinicians and lay people. Participants in this study wished to consider costs before deciding when people should start treatment

Many people dislike the concept of taking pills every day, and might choose lifestyle change rather than medication, if possible. Some people want only a perfect treatment, with guaranteed effectiveness and no possible adverse effects

The diversity of beliefs makes consensus unlikely, and guidelines should reflect this. True dialogue is required if patients' preferences are to be used to make decisions

true dialogue between clinicians and patients before embarking on lifelong preventive treatment.

We thank the participants, who gave up their time to be interviewed, and Fiona Johnstone who advised on recruitment. Contributors: See bmj.com
Funding: DKL was funded by a North West Regional Health Authority Public Health Fellowship.

Competing interests: None declared.

Ethical approval: The study was approved by the local research ethics committee.

Haynes RB, Devereaux PJ, Guyatt GH. Clinical expertise in the era of evidence-based medicine and patient choice. Evid Based Med 2002;7:36-8.
Royal Pharmaceutical Society of Great Britain Working Party. From compliance to concordance: achieving shared goals in medicine taking. London: Royal Pharmaceutical Society of Great Britain, Merck, Sharp and Dohme, 1997.

3 Benson J, Britten N. Patients' decisions about whether or not to take antihypertensive drugs: qualitative study. BMJ 2002;325:873-7.

Svensson S, Kjellgren KI, Ahlner J, Saljo R. Reasons for adherence with antihypertensive medication. Int J Cardiol 2000;76:157-63.

5 Barber N. What constitutes good prescribing? BMJ 1995;310:923-5.

6 British Cardiac Society, British Hyperlipidaemia Association, British Hypertension Society, endorsed by the British Diabetic Association. Joint Hypertension Society, endorsed by the British Diabetic Association. Joint
British recommendations on prevention of coronary heart disease in British recommendations on prevention of
clinical practice. Heart 1998;80(suppl 2):S1-29.

7 Department of Health. National service framework for coronary heart disease. London: DoH; 2000.

8 Lupton D. Perspectives on power, communication and the medical encounter: implications for nursing theory and practice. Nurs Inq 1995;2:157-63.

9 British Cardiac Society, British Hyperlipidaemia Association, British Hypertension Society, endorsed by the British Diabetic Association. Joint British recommendations on prevention of coronary heart disease in clinical practice. Heart 1998;80(suppl 2):S1-29.

10 Department of Health. National service framework for coronary heart disease. London: DoH; 2000.

11 Lewis DK, Barton S. Who decides when to start preventive treatment? A questionnaire survey to compare the views of different population subgroups. J Epidemiol Community Health 2003;57:241-2.

12 Steel N. Thresholds for taking antihypertensive drugs in different professional and lay groups: questionnaire survey. BMJ 2000;320:1446-7.

13 Protheroe J, Fahey T, Montgomery TJ. The impact of patients' preference on the treatment of atrial fibrillation: observational study of patient based decision analysis. BMJ 2000;320:1380-4.

14 McAlister FA, O'Connor AM, Wells G, Grover S, Laupacis A. When should hypertension be treated? The different perspectives of Canadian family physicians and patients. Can Med Assoc J 2000;163:403-8.

15 Montgomery AA, Harding J, Fahey T. Shared decision making in hyperMontgomery AA, Harding J, Fahey T. Shared decision making in hyper-
tension: the impact of patient preferences on treatment choice. Fam Pract tension: the imp

16 Kjellgren KI, Ahlner J, Saljo R. Taking antihypertensive medicationcontrolling or co-operating with patients? Int J Cardiol 1995;47:257-68.

17 McKinstry B. Do patients wish to be involved in decision making in the consultation? A cross sectional survey with video vignettes. $B M$ J 2000;321:867-71.

18 Britten N, Stevenson FA, Barry CA, Barber N, Bradley CP Misunderstandings in prescribing decisions in general practice: qualitative study. BMJ 2000;320:484-8.

(Accepted 28 July 2003)

\title{
Commentary: A small study, but the results ring true
}

Robert Johnstone

Arthritis and Rheumatism International, 14 Hazel Lane, Skelmersdal WN9 6UN Robert Johnstone president
My own lifetime experience of chronic illness and my role as president of Arthritis and Rheumatism International, a trustee of the Long Term Medical Conditions Alliance, and vice chair of Disabled Living Centres Council indicate that my experience, although unusual, is highly relevant to the issues raised by Lewis and colleagues. I know that many patients wish to avoid drugs and would prefer lifestyle changes, and they want to minimise side effects from treatment. Thus, any preventive treatment would have to have minimal intrusion on quality of life for patients to pursue such a strategy. A well researched treatment that met these criteria and which increased patients' capacity to enjoy life and to manage their own condition would be uniquely valuable.

For nearly 48 years, since the age of 3 , I have been pursuing a variety of treatments for severe juvenile rheumatoid arthritis. My role in this process has evolved from initially subservient compliance with my
NHS general practitioner and consultant to a dominant partnership in my own health care. Rough calculations indicate that, between 1956 and 1976, I took 40000 aspirin and 20-30000 other pills (prednisolone, phenylbutazone, mepacrine, etc).

The trigger for my taking responsibility for my own body was through learning transcendental meditation while at university in 1973. Direct benefits in pain reduction, increased mobility, and blossoming self confidence coupled with encouragement from a friendly retired surgeon allowed me to gradually eliminate all drugs. My rheumatologist was furious: "I gave you permission to vary the dose, not stop altogether." I changed consultant rather than try to work with a man who made no attempt to listen to my views and showed no understanding of my values.

Many years on, I have a warm relationship with two general practitioners who themselves meditate but only an impersonal annual visit to my consultant. My 
general practitioners, who are both qualified in maharishi vedic medicine, treat me as an equal, and we exchange views frankly and freely. I can take their advice on issues I raise, and they can suggest options without the slightest hint of offence if I decline. My use of maharishi ayurveda herbal preparations, lifestyle changes (diet, frequent swimming, etc), and regular meditation mean that I minimise the possibility of side effects and maximise my resistance to future problems.

My only real criticism of this paper by Lewis and colleagues is that such a small number of people were interviewed. Based on my own experience, I would like to amplify some points from their research.

- True dialogue between patient and doctor is essential, and patients' preference and values must be respected

- Patients want to make decisions to maximise their quality of life, and negotiated prescribing will yield better outcomes than imposed treatment

- Doctors will tend to have different values from patients, but the imbalance of power in the doctor-patient relationship causes them to have undue influence. To counter this, I would recommend that greater emphasis be placed on listening skills in doctor training and that more opportunities for "expert patient" training be provided on a routine basis

- People dislike unnecessary drug taking and would prefer lifestyle changes to "imperfect treatment." (Is there such a thing as perfect treatment?) Unnecessary drug taking, which could include preventive treatment, can lead to the feeling of loss of control over health and reduce wellbeing, with subsequent negative impact on physical and mental health

- There is an urgent need to research those who decline treatment, and to provide alternative options including complementary therapies as required

- Finally, the cost of treatment is a huge issue. Cost is the biggest problem facing me, as I am living on a low income from incapacity benefit and income support. NHS treatments would be free, but herbal options and lifestyle choices cost money. Perhaps the NHS should fund well researched and patient friendly solutions such as transcendental meditation and maharishi ayurveda for those with chronic conditions.

\title{
Changes in use of hormone replacement therapy after the report from the Women's Health Initiative: cross sectional survey of users
}

\author{
Beverley Lawton, Sally Rose, Deborah McLeod, Anthony Dowell
}

In 2002 the Women's Health Initiative reported the results of a study on the effects of combined oestrogen plus progestogen on healthy postmenopausal women. They found increased rates of breast cancer, coronary heart disease, stroke, and venous thromboembolism and decreased rates of hip fracture and colorectal disease but no "global" benefit. They concluded that combined oestrogen and progestogen is not suitable for the prevention of chronic diseases. ${ }^{1}$ The subsequent extensive media coverage came at a time when the prevalence, ${ }^{23}$ duration, ${ }^{24}$ and use of hormone replacement therapy (HRT) for the prevention of chronic disease had been increasing. ${ }^{2}{ }^{4}$ After the report, government regulatory authorities issued advice to health professionals and women, and guidelines relating to the postmenopausal use of hormone replacement therapy were updated. ${ }^{5}$ We examined changes in HRT use since the publication of the report.

\section{Participants, methods, and results}

Between January 2000 and November 2002, 3500 women were screened from 23 general practices in four New Zealand centres as part of the recruitment process for the women's international study of long duration oestrogen after menopause (WISDOM) and a New Zealand observational study. We surveyed 998 women who were using HRT at the time they were screened but who were ineligible or unwilling to join the international study.

We sent participants an information sheet and questionnaire by post six months after the trial results were published. One reminder questionnaire was sent to non-responders, and 810 surveys $(81 \%)$ were completed and returned. In total 776 respondents were taking HRT when the trial results were published and were eligible for inclusion. No significant differences were observed between non-responders $(\mathrm{n}=188)$ and responders $(\mathrm{n}=776)$ regarding age $\left(\chi^{2}=2.89, \mathrm{df}=3, \mathrm{P}=0.41\right)$ and education $\left(\chi^{2}=1.78\right.$, $\mathrm{df}=3, \mathrm{P}=0.62)$. Non-responders were more likely than responders to have taken HRT for less than five years $\left(\chi^{2}=9.71, \mathrm{df}=2, \mathrm{P}=0.008\right)$. The table shows the analyses for the 734 respondents for whom we had complete data on HRT use.

We analysed data using SAS Insight and estimated associations between a range of independent variables and the dependent variables (stopping and restarting HRT) from a generalised linear model with a log link and binomial errors. Independent variables included women's age at the time of the survey, type of HRT, years of HRT use, hysterectomy status, education, and reasons for starting HRT.

Of the 734 respondents, 423 (58\%) stopped taking HRT. Of the 423 who stopped when the results were published, $132(18 \%)$ had restarted at the time of our survey and 291 (40\%) had not. Most respondents (610, $83 \%$ ) reported that they had discussed HRT with a
Department of General Practice, Wellington School of Medicine and Health Sciences, PO Box 7343, Wellington South, New Zealand Beverley Lawton senior research fellow Sally Rose research fellow Deborah McLeod research director Anthony Dowell professor of general practice

Correspondence to: B Lawton wnmeds.ac.nz

BMJ 2003;327:845-6 